\title{
EDITORIAL
}

\section{The Health of Geriatrics in Canada -More Than Meets the Eye}

Ken M. Madden, MSc, MD, FRCPC, Editor-in-Chief, Canadian Geriatrics Journal and Roger Y. Wong, BMSC, MD, FRCPC, FACP, President, Canadian Geriatrics Society

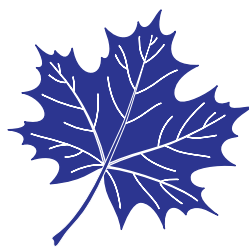

Division of Geriatric Medicine, University of British Columbia, Vancouver, BC

DOI:http://dx.doi.org/10.5770/cgj.16.75

Much has been written about the "grey tsunami",(1) an ongoing demographic shift with profound consequences for the Canadian health-care system. Since Geriatric Medicine was accredited by the Royal College in 1977, the field has steadily developed into a dynamic array of clinical, educational, and research activities. By 2051, one in four Canadians is expected to be over the age of $65,{ }^{(2)}$ providing both opportunities and challenges for the specialty of Geriatric Medicine in Canada.

Public awareness of the "greying" Canadian population has increased the receptiveness of all levels of government for the need for geriatric services. In fact, the accelerating need for older adult care and the multidisciplinary skills of geriatricians have allowed geriatric medicine specialists to "punch far above their weight" in terms of leadership in health-care administration. ${ }^{(3)}$ This has allowed a move in Canada towards more elder-friendly hospitals and an increased use of Acute Care of the Elders (ACE) units. Since its first report in the literature, ACE units have been implemented in various jurisdictions across Canada to provide hospitalized elders with patient-centered care, frequent medical review, elder-friendly environment, early rehabilitation, and enhanced discharge planning. ${ }^{(4)}$ Older adults who are served by ACE units represent a particularly vulnerable or frail cohort, as many of them are prone to developing adverse health outcomes even after hospitalization. ${ }^{(5)}$ This has not been an easy endeavour, as comprehensive geriatric care for vulnerable older adults is neither straightforward nor inexpensive. Geriatricians are effective in influencing health-care changes due to their versatility and broad-based multidisciplinary networking. The option of not making specialized geriatric care available to Canadians in an equitable manner is simply not acceptable from a social responsibility and accountability point of view.

However, there are challenges that come with administrative success; every geriatrician improving overall senior's care at the administrative level is one less geriatrician consulting on individual patients. Certainly with an average ratio of 0.50 geriatric medicine specialists per 10,000 older adults, there is ample room for growth and recruitment. ${ }^{(6)}$ In fact, the current and expected employment difficulties in several specialties (including cardiac surgery, neurosurgery, and orthopedic surgery, plus other specialties that have raised concerns) provide new opportunities for recruiting future trainees to our rapidly growing field. ${ }^{(7)}$

The future of aging research in Canada has improved greatly over the last decade. One of the challenges for gerontological researchers was that they were forced to apply to specialized committees that were not always sympathetic to the discipline, or did not appreciate the multidisciplinary quality of aging research. The funding environment has greatly improved since the formation of the Institute of Aging. In 2000-2001, $6 \%$ (\$15.6 million) of CIHR total expenditures were invested in open grants for aging-related research. In 2009-2010, the proportion of CIHR grant expenditures in these areas rose to $13 \%$ ( $\$ 61$ million) of total expenditures for open grants. ${ }^{(8)}$ This increase in direct funding has also indirectly assisted Canada's gerontological researchers in leveraging funds from other granting agencies. Knowledge translation of Canadian discoveries into practice has also improved, as shown though direct CIHR initiatives ${ }^{(8)}$ and though the formation of a new, open-access National Library of Medicine indexed journal (the Canadian Geriatrics Journal). ${ }^{(9)}$

The future of education in Geriatrics has also improved in recent years, although there is certainly room for further development. Many geriatricians in Canada are well-positioned to help move Geriatrics education forward since they hold important educational leadership positions at their home institutions ranging from course directors to program directors to decanal appointments. There are now national core competencies in Geriatrics identified for undergraduate medical students, and future efforts should focus on increasing exposure to geriatric care across postgraduate residency programs. While the numbers of residency training positions in both Geriatric Medicine programs and Care of the Elderly programs have seen general increases at many Canadian universities, not all residency positions in these programs are being filled. ${ }^{(10)}$ This is likely a multi-factorial issue that warrants further exploration, and trainee selection is a major determinant. The Canadian Geriatrics Society is actively engaged in several strategic programs to improve the image of Geriatrics among medical trainees, including the 
Resident Geriatrics Interest Group (RGIG) for residents and the National Geriatrics Interest Group (NGIG) for medical students. These programs are centrally facilitated and wellsupported by local chapters.

In many ways we can describe the overall health of Geriatrics in Canada as reasonably good, and we recognize that there is room for improvement in the clinical, research, and educational arenas. The challenges are real, and yet we believe the future looks promising. We simply cannot afford to think otherwise as we join forces with other stakeholders to meet the health-care needs of the aging population in Canada.

\section{REFERENCES}

1. Christensen K, Doblhammer G, Rau R, et al. Ageing populations: the challenges ahead. Lancet. 2009;374(9696):1196-208.

2. Sheets DJ, Gallagher EM. Aging in Canada: state of the art and science. Gerontologist. Published online Nov. 29, 2012. doi: 10.1093/geront/gns150

3. Baerlocher MO, Detsky AS. Who's doing what? Time spent on committee and administrative work. CMAJ. 2006;174(12):1703.

4. Landefeld CS, Palmer RM, Kresevic DM, et al. A randomized trial of care in a hospital medical unit especially designed to improve the functional outcomes of acutely ill older patients. N Engl J Med. 1995;332(20):1338-44.
5. Wong RY, Miller WC. Adverse outcomes following hospitalization in acutely ill older patients. BMC Geriatr. 2008;8:10.

6. Hogan D, Borrie M, Basran J, et al. Specialist physicians in geriatrics: report of the Canadian Geriatrics Society Physician Resource Working Group. Can Geriatr J. 2012;15(3):68-79.

7. Padmos A. Understanding specialist unemployment: identifying causes and clarifying misunderstandings. Message from the CEO Royal College of Physicians and Surgeons 2012. Available from: http://ceomessage.royalcollege.ca/2012/11/28/ understanding-specialist-unemployment-identifying-causesand-clarifying-misunderstandings/

8. Martin-Matthews A, Mealing L. Realizing the vision. The Canadian Longitudinal Study on Aging as a strategic initiative of the Canadian Institutes of Health Research [editorial]. Canadian J Aging. 2009;28(Special Issue 3):209.

9. Hogan DB. Begat and begone. Can Geriatr J. 2011;14(1):1.

10. Wong RY. Rising to the challenge. How postgraduate medical education in Canada is preparing future physicians to look after aging Canadians. Gravitas. 2011;44(3):12-13.

Correspondence to: Ken M. Madden, Gordon and Leslie Diamond Health Centre, 7th Floor, 2775 Laurel Street Vancouver, BC, V5Z 1M9 Canada

E-mail: kmmadden@interchange.ubc.ca 